\title{
The Myth of Balance: Exploring Community-based Ecotourism in Hong Kong
}

\author{
Dantong Zhang ${ }^{1}$ \\ ${ }^{1}$ Department of Humanities and Creative Writing, Hong Kong Baptist University, 999077 Hong Kong, China
}

\begin{abstract}
This paper examines the community-based ecotourism on Yim Tin Tsai which is a representative example of Hong Kong's responsible management. The island presents a local community of the explored saltpan and natural resources. The research draws upon criticism of ecotourism in Yim Tin Tsai as a way of understanding the importance of balancing nature with the economic interests. As adopting a qualitative research method for the case study, the experience and thoughts reflected by the local resident of will be also analyzed.
\end{abstract}

\section{Introduction}

Yim Tin Tsai is an island with saltpans and different plants, located in Sai Kung (Hong Kong SAR). The island has existed for more than 300 years, it was originally established by a Hakka family which is Chan clan, and the production of salt was the major economic activity in the old days. After the island became deserted because of the migration of local villager in the $1950 \mathrm{~s}$, the community involvement allowed the salt fields resurrected and later on it earned a UNESCO award for its educational resources and industrial heritage. The village has attracted many visitors to explore the religious, culture and natural landscape (Agapito \& Chan, 2019). One of the present versions is to have the responsible tourism management parties to upgrade the sustainable use of local resource through making sure its enjoyment for the future generations (Frey \& George, 2010). The communitybased ecotourism is one of the approaches that has been advocated in order to cater for a more sustainable ecotourism industry. Additionally, the participation of the shareholders is also one of the responsible manners to achieve the aim. Project involving the participation of the community indicates a form of voluntary action in which the individuals confront opportunity of citizenship (Tosun, 2000).

\section{Theoretical Background}

Adopting a responsible tourism approach shall be based on offering better experience to the visitors as well as providing business opportunities for improving the quality of life of the local citizens. The approach focuses on several aspects: (1) monitor and assess the impacts of tourism development, (2) create and make good use of the competitive advantages, (3) ensure the involvement of relevant parties or economic linkage, (4) encourage the diversity of natural, social, cultural and economic development, (5) promote the sustainable local resource use and enjoyment of the citizens.

The community-based project may encompass various forms of community participation (Tosum, 1999). Despite of fact that some people think there are barriers in using the approach to do research project, it is still considered to be one of the good ways to achieve sustainable tourism development. The public and the local community is the driving force to protect the natural environment. Ecotourism is confused with such terms as alternative, sustainable and green tourism (Wight, 1995). However, not all ecotourism is sustainable, and some people even think it as solution to the problem of mass tourism, it cannot be like that. Ecotourism is a new and young industry and some cases on the negative impacts and mismanagement has already documented (Boo, 1991). Some problems may cause some ecotourism operations unsustainable since some useful principles to ecotourism cannot be incorporated into its conception and development. But ecotourism can provide an approach to conservation-oriented tourism.

\section{Research Methodology}

A case study approach was followed in order to carry out this research (Yin, 2004). Data were collected by using both primary and secondary recourses to form the case study (Stake, 1995). Some secondary source like web pages, news and official documents were consulted and read for this research. This study also adopts a qualitative research method in understanding the thoughts of the local residents in the village. A group of 3 undergraduate students visited Yim Tin Tsai in mid-November 2020 and interviewed one of the local residents. The consent of the participant was sought in terms of recording the interview process and taking photos. Initial questions were prepared to guide the interview, but as the interview proceeded, it 
was more like a conversation. In order to getting to know the participant's experience, one open-end question was also designed to assess the perceived emotions.

\section{Findings and Discussions}

The small offshore called Yim Tin Tsai is a traditional Hakka village, it also shows what it means by East meet West. It was different from a conventional Chinese style village because it is also a Catholic community. There were about 300 residents lived on the island in the 1920 s. But due to the adverse situation of rural life, many villagers moved to the urban areas and overseas counties (Agapito \& Chan, 2019). In the 1990s, the place was abandoned, but several members from the Chan's clan, who shares the same cultural identity gathered together and strive to contribute to the rejuvenation of the village (Agapito \& Chan, 2019). Now the village become s tourism attraction, when the saltpan was listed in 2015 Asia-Pacific Heritage Awards by UNESCO, the number peaked at 37,000 in 2016 . At present, the salt production is pending for the approval of the government for public sale.

We were lucky to find a local villager since most of the people we met there are social workers. The interview took around 30 minutes and it was conducted outside of the School and Heritage Centre. Our participant Sara (pseudonyms) is a local resident who was born in this village and now she is working at Yim Tin Tsai as a receptionist.

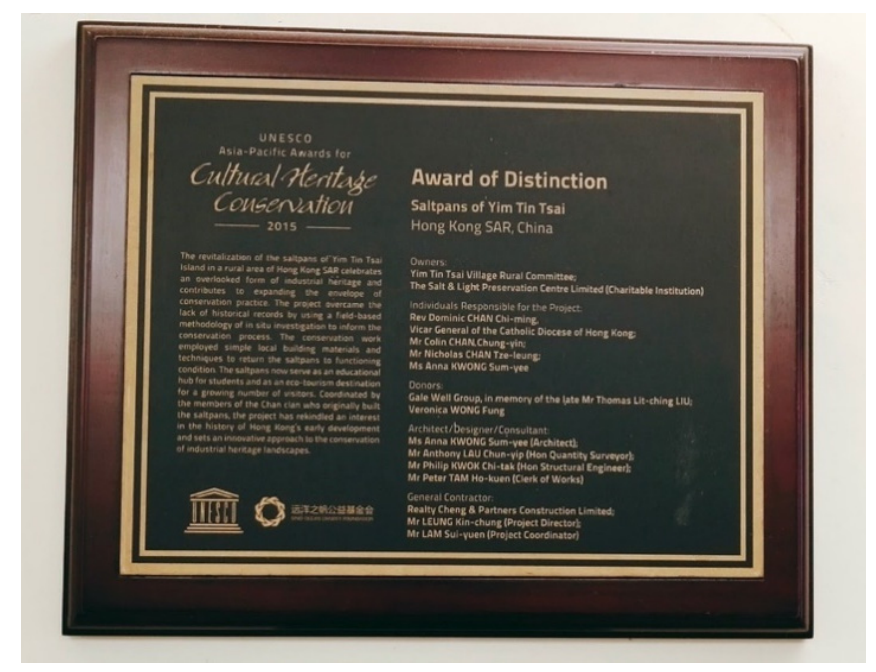

Fig. 1. Asia-Pacific Heritage Awards by UNESCO

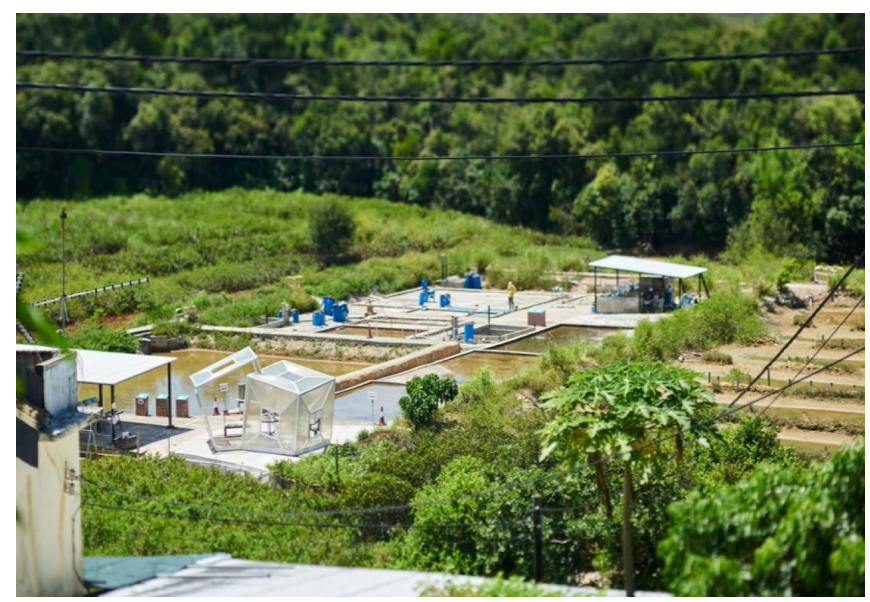

Fig. 2. The saltpan

"Actually, I don't like to have too many visitors coming into the island, because this will disturb the tranquility of the island and cause damage to the environment." For Sara, the problem is about balancing. More things should be done to help tip the balance from predicament to panacea. She told us that the village is a land of idyllic beauty, but as the number of the tourist increase, she has been seeing some incorrect tourism behaviors that damages the cultural landscapes. Inappropriate conducts like planting picking, littering as well as disturbing animals can easily harm the nature environment of the island. Some tour participants are not at all genuine ecotourists, and some local travel agent often named their products as ecotours in order to attracting more visitors and patrons, and to reduce the cost, untrained guides are employed so they may fail to provide proper ecotourism services. The lack of knowledge in environmental conservation may lead to inconducive tours and reduce the effect of dissemination of the proper behaviors in Yim Tin Tsai (Cheung \& Jim, 2013). Sara believes that people should resist the tendency to emphasis the economic aspects, in other words, what matters most 
is the mindset. The visitors' quality and their behaviors in this regard should be underlined in order to minimizing the risk of degrading nature.

We found her ideas are quite thought-provoking, but the question is how to tackle the challenges encountered? The challenges shall be to incorporate all goals, let the economic and social developed in a balanced fashion. Expect for setting rules for the tourists, underpinning the ethics-based principles can be a way out. According to Weight (1995), one of the ecotourism codes includes encouraging all parties(e.g.government,non-organization and tourists) for the recognition of intrinsic values of the resource and involve education among the groups before, during and after the trip. And to ensure the responsible environmental practices are applied in an efficient manner, people need to pay attention to both the External (natural and cultural) resources as well as the Internal operations(Weight, 1995). The ecotourism codes have been adopted by countries like the United States, Canada and Australia, it offers a general guidance for the operators and tourists. Hong Kong ecotourist are less concerned about site facilities, they prefer places with high ecological value and better management. Recently, Hong Kong government has developed nature-orientated tourism by constructing large scale infrastructure like the Wetland Park. But focusing on the improvement of modern facilities seems hard to attract the true ecotourists or oversea ecotourists because it may not help to modify the deep-rooted perception of Hong Kong as an urban shopping destination (Cheung \& Jim, 2013).

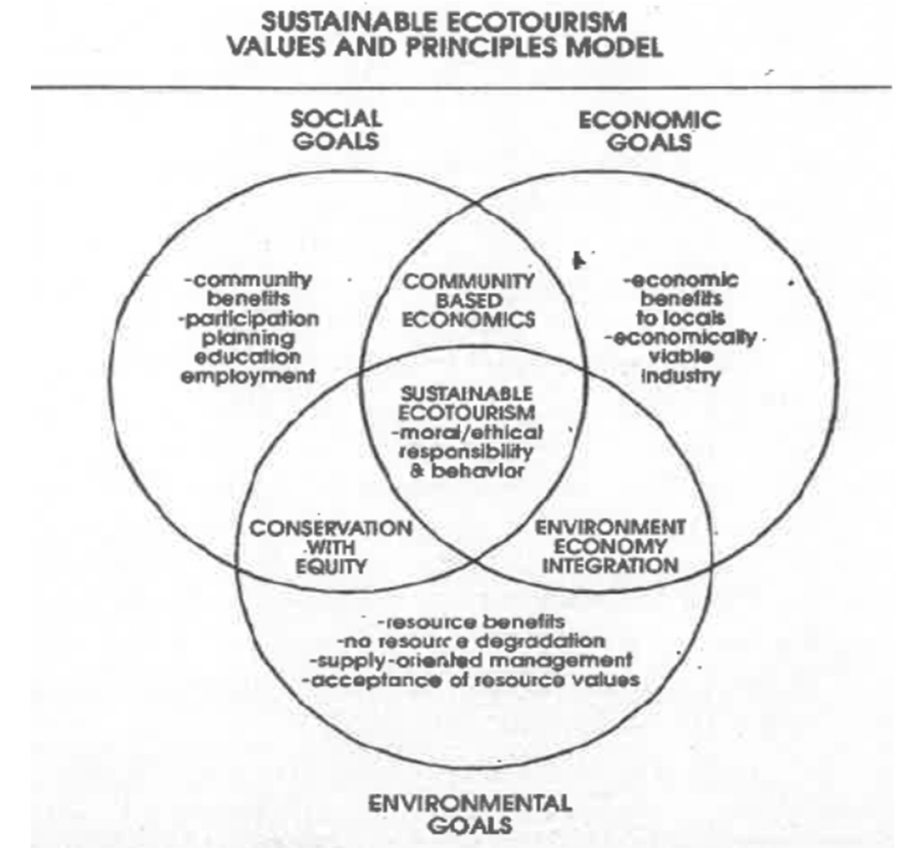

Fig. 3. Sadler, 1990

\section{Conclusion}

Yim Yin Tsai is a place where community-based ecotourism approach has been developed, the Hakka culture and natural-based assets. The preliminary findings of this study suggests that the visitor flow can help the island economically, but through the discovery from the interview, it seems clear that more efforts should be made by all parties in order to resist over tourism. People tend to hold a demand-oriented view and try to offer a consumptive and impatient market, therefore failing to understand the interrelatedness of the elements in the environment. That is perhaps why it is important to adopt ethic and valued-based approach in order to realize a balance between natural and economic development. Therefore, this could be ascertained if public education can help to nurture more genuine ecotourists (Cheung \& Jim, 2013). More research in the future can be done in filling the knowledge gap and inform parties and the government to come up with optimized relevant policies.

I wish to thank the classmates from Hong Kong Baptist University who joined me in the field trip to Yim Tin Tsai, without their help I could not reach this far. I also want to express my gratitude for the great support kindly provided by my friends and family.

\section{References}

1. Agapito, A., \& Chan, C. S. (2019). The contribution of a multisensory approach to responsible management in community-based tourism: the case of Yim Tin Tsai village in Hong Kong. Advances in Hospitality and Tourism Marketing and Management. University of Portsmouth Press. Retrieved from https://www.researchgate.net/publication/334626418 The Contribution of a Multisensory Approach t o_Responsible_Management_in_Communitybased Tourism The Case of Yim Tin Tsai Villag e in_Hong_Kong

2. Boo, E. (1991). Pitfalls and liabilities of ecotourism development: Proceeding of the 1991 World Congress on Adventure Travel and Ecotourism. The Adventure Travel Society Inc. Colorado 145-149.

3. Frey, N., \& George, R. (2010). Responsible tourism 
management: the missing link between business owner's attitudes and behavior in the Cape Town tourism industry. Tourism Management. pp. 621-628.

4. Lewis T. O. Cheung \& C. Y. Jim. (2013). Ecotourism service preference and management in Hong Kong. International Journal of Sustainable Development \& World Ecology. Retrieved from https://www.tandfonline.com/doi/full/10.1080/13504 509.2013.775192? scroll=top\&needAccess $=$ true

5. Sadler, B. (1990). Sustainable development, northern realities and the design and implementation of regional conservation strategies. University of Calgary Press.

6. Tosum, C. (1999). Limits to community participation in the tourism development.

7. Wight, P. (1995). Sustainable ecotourism: balancing economic, environment and social goals with an ethical framework. Tourism Recreation Research. Retrieved from https://www.researchgate.net/publication/313016839 Sustainable ecotourism_Balancing_economic envi ronmental_and_social_goals_within_an_ethical_fra mework

8. Yin, R. (2014). Case study research. London: Sage Publications. 